\title{
Medical case reports in Late Modern English
}

\section{Lehto, Anu Elina}

John Benjamins

2019

Lehto , A E \& Taavitsainen , I A J 2019 , Medical case reports in Late Modern English . in I Taavitsainen \& T Hiltunen (eds), Late Modern English Medical Texts : Writing medicine in the eighteenth century . John Benjamins , Amsterdam , pp. 89-111 . https://doi.org/10.1075/z.221.05leh

http://hdl.handle.net/10138/326155

https://doi.org/10.1075/z.221.05leh

acceptedVersion

Downloaded from Helda, University of Helsinki institutional repository.

This is an electronic reprint of the original article.

This reprint may differ from the original in pagination and typographic detail.

Please cite the original version. 


\title{
Medical case reports in Late Modern English
}

\author{
Anu Lehto \& Irma Taavitsainen \\ University of Helsinki
}

This chapter shifts the focus to the patients, using discourse analysis. The medical case report is a narrative of a single case of disease or injury and it is one of the genres that have continuity throughout the history of English medical writing from the late medieval period to the present. However, its functions and linguistic realizations vary in different periods. Attention will be paid to the degree of conventionalization in the genre developments and the perspective through which the narrative is told. The method relies on both quantitative corpus linguistic and qualitative discursive analysis. The period and this century represent a transition from the earlier thought styles to more modern approaches to medicine. The first statistical assessments appear toward the end of the eighteenth century. The study traces how the developments in medical thinking are reflected in case narratives of different layers and fields of medical writing. The linguistic form of case studies varies considerably between different text categories, in particular specific treatises, surgical and anatomical texts, public health, and periodicals, and they are often embedded in longer texts within other genres. Instruction was the most common purpose of writing and continues in the eighteenth century, but new functions emerge as well, as the case reports demonstrate new methods of treatment and cures, and patients begin to record their own experiences as patients. This shift of angle is noteworthy, as for the first time we have "ego-documents" of the kind.

\section{Introduction}

A case study is a narrative of a single case of disease or injury and can be combined to dual or multiple case studies. The patient's disease is usually described from the onset to the outcome, most often recovery or death, and the ensuing amount of details may vary. Case studies can be regarded as an essential constituent of medical writing with a long history in the vernacular from the late medieval period to the present, and we can assume that the development of the genre reflects changes in the underlying thought styles. The present study traces diachronic changes and continuities in case studies aimed at professional and/or lay audiences by examining their structure, prevailing linguistic patterns and points of view. At the same time, we demonstrate the potentials of the database, as the corpus has a wide coverage of case reports in different varieties within the register of medical writing and is large enough to allow an assessment by decades.

Case studies belong to the practical side of medicine. The roots of the genre lie in Latin case reports, consilia and practica, presenting typical manifestations of illness and giving advice on how afflicted patients should be treated. The genre was transferred into English in the earliest phase of vernacularization in the late medieval period and has continuity throughout its history first as the core genre of medical teaching but then more in the periphery, reporting rare and unusual cases. In tracing its history, the eighteenth century provides a challenge, as it was a period of great changes and the field is still largely uncharted. 
The most important function of case reports in the eighteenth century was the same as before, and most case reports describe typical progressions of illness, specifying symptoms and describing healing methods and the outcome that was achieved, but some innovations can also be encountered. Case studies often finish with broader views and generalizations on what could be expected in the future in similar cases. Such "predictions" on a more abstract level are not encountered earlier. The genre achieved a variety of additional functions, too. Case studies could be used for testifying the efficacy of the applied cure, and there is a partial overlap with medical advertisements. A novel feature is that case reports intertwine with experiments in some texts; this feature is connected with the author's search for new cures and more precise information on diseases. Some more unusual cases satisfy their readers' curiosity for sensation. Thus, a diversity of material with case reports is present and instead of one main line of development, there are several.

\section{Earlier studies}

The genre of case studies has a long history whose outline has been charted for the earlier centuries with Middle English Medical Texts (MEMT) and Early Modern English Medical Texts (EMEMT) (1375-1700) and for later times (1850-1995), but there is a gap in the eighteenth century to be filled in with this study on LMEMT. Earlier articles deal with the structure, the point of view and the author's role in the diachronic developments of the genre within the late medieval and early modern periods (Taavitsainen 2011; see also Class 2014). The assessment of more modern case studies begins from the mid-nineteenth century with the establishment of The British Medical Journal and The Lancet and covers the development to the end of the twentieth century (Taavitsainen and Pahta 2000). The results show that nineteenth-century case reports contain affective language and that the author's presence is prominently intertwined with the patient's story, while in the twentieth and twenty-first centuries the doctor remains in the background, while clinical facts and procedures are foregrounded. Atkinson's (1992) comprehensive article on case reports and research articles in the Edinburgh Medical Journal (hereafter EMJ) 1731-1985 overlaps with the present study by seven decades, but his data comes solely from the most innovative medium of the time, the new scientific medical periodical for top professionals (see also scientific periodicals category description). Furthermore, he assessed texts at forty-year intervals, and his focus was on the evolution of the modern research article and case studies are considered from this angle. In contrast, our material covers all possible layers of medical writing for the whole eighteenth century with all its varieties, and the number of case studies is much higher (262). ${ }^{1}$ According to Atkinson (1992: 349), case studies in the EMJ became more conventionalized after 1775 and acquired a fairly regular seven-step structure: information on the patient, his/her history, examination of the patient, first treatment and its effect, a possible second round of treatment, course of illness, and outcome. Additionally, a development towards more distinct sectioning took place and the parts of case studies acquired different functions. Our data is more varied and shows more diverse developments according to sociolinguistic background factors.

\section{Approach and aim of the study}

\footnotetext{
${ }^{1}$ Atkinson (1992) studied six types of medical articles in the EMJ: case reviews, research reviews, treatment-focused reports, experimental reports and speeches, as well as other medical articles. He further subjected 70 of the texts into multidimentional analysis, and 20 of these medical texts, including case studies, come from the eighteenth century.
} 
The present analysis continues to map diachronic developments of case studies from the early modern to the late modern period, and we aim at relating the genre of medical case reports to the overall field of medical writing in the eighteenth century. Case studies belong to the narrative text type (see Werlich 1983), and the purpose of our analysis is to record the structure of the case studies. ${ }^{2}$ Structural regularities that stem from the earlier periods can be expected in the perspective through which the narrative is told. Additionally, the study records the prevalence of case studies in medical writing in different corpus categories of LMEMT. Involvement and personal affect features are of special interest to us, and we rely on Fowler (1986) and Simpson (1993) for the theory. In general, scientific writing and medical prose evolved diachronically toward the present academic style of writing with passive constructions, complex prepositional phrases and nominalizations, displaying few references to the context of writing (Biber 1995: 297), thus pointing to a development towards a more detached style of writing. Our results, however, show that eighteenthcentury case reports vary in their degree of authorial involvement and affect from highly personal accounts to more distanced styles.

Our general approach is discourse-analytic combined with corpus linguistic methodology. Case reports were located in the corpus along with qualitative reading and corpus linguistic searches were also applied. In our analysis, we pay attention to narrative patterns and lexis with both qualitative contextual analysis and quantification (see below). The structure of the case studies is analysed by qualitative assessment, while features of personal involvement are charted by corpus linguistic methods. Additionally, the findings were related to the sociolinguistic background parameters of authors and audiences and considered in the wider sociohistorical context of the period.

\section{The sociocultural background}

Our focus is on communication and dissemination of knowledge in its sociohistorical frame. The context in which case studies were composed plays an important role in all its aspects and levels, from the broad cultural and sociohistorical context to situational and textual contexts and to the narrow linguistic context. A great deal happened in the history of medicine in the eighteenth century, leading towards stricter professionalization, the advent of statistical assessments and laboratory medicine. The "new science" of the previous century had launched the Matter-of-Fact principle with the requirement that experiments should be replicable and objective (see Dear 1991); this is reflected in case studies, too. Knowledge of human anatomy increased with empirical evidence from post mortem autopsies that provided a basis for improvement in surgical techniques. Further, institutional developments helped to advance medical science.

New channels for the dissemination of medical knowledge were founded and specialized medical journals for academic use changed the scene in a drastic way, although all this did not happen overnight. Scientific and medical periodicals provided a new medium for disseminating knowledge and accelerated the pace of medical news and knowledge distribution in periodical issues coming out regularly, mostly on a monthly basis. At the same time, the first steps were taken towards the

\footnotetext{
${ }^{2}$ Werlich (1983: 39-41) classifies texts into five types according to their discourse function (narration, description, exposition, argumentation, and instruction), and the purpose of narration is to report actions in time. The text types are distinguished according to text-internal linguistic features, and each text type relies on prototypical linguistic elements. Early modern narratives typically follow the pattern of natural narratives, i.e. events are recounted in the order in which they have occurred in the text-external reality (e.g. Taavitsainen 2011).
} 
first mass media in newspapers for the newly literate social classes (see Conboy 2017). However, the majority of medical writings followed the more traditional publication practices with monographs that could take years to prepare. The period introduced a radically new practice in this respect, but also widened the perspective in another sense. For the first time in the history of medicine, two-way communication is found in letters-to- the-editor in The Gentleman's Magazine (GM) (see Chapter 7 in this volume). Patients had started to record their own experiences in egodocuments already in the previous century, ${ }^{3}$ but the practice becomes more common in the eighteenth century. These various developments are likely to have influenced styles of medical writing as well.

\section{Selection of case studies}

The material for the study has been collected across all corpus categories. The case studies were retrieved by corpus searches and qualitative reading. Search words such as case, story, patient, woman, man, $M r$, child, year, and age were used, as qualitative assessment indicated that these words frequently appear in case studies; more were located by qualitative reading. The analysis comprises 262 case reports distributed over 66 texts. Most cases appear in the categories for specific treatises, surgical and anatomical texts and scientific periodicals, while a few instances of the genre were present in general treatises, regimens, and public health. Further, no examples were found in medical recipe collections. All case studies found in the corpus were considered in our analysis; however, as Atkinson (1992) focuses on case studies in the periodical EMJ, we made an exception, as instead of all case studies in scientific periodicals, we gathered only a selection of 51 texts from different decades by manual picking for a systematic diachronic coverage of this category. The number of analysed case studies can be seen in the following table:

Table 1. Distribution of analysed case studies over each corpus category and text

\begin{tabular}{|l|c|c|c|}
\hline \multicolumn{2}{|l|}{ Corpus category } & $\begin{array}{r}\text { Number of } \\
\text { case studies }\end{array}$ & $\begin{array}{r}\text { Distribution of case } \\
\text { studies over texts }\end{array}$ \\
\hline \multirow{2}{*}{ General treatises } & 3 & 2 \\
\hline \multirow{3}{*}{$\begin{array}{l}\text { Treatises on } \\
\text { specific } \\
\text { topics }\end{array}$} & Diseases & 26 & 11 \\
\cline { 2 - 4 } & Methods & 67 & 7 \\
\cline { 2 - 4 } & Medicines & 57 & 8 \\
\cline { 2 - 4 } & Midwifery & 21 & 3 \\
\hline Recipes & 0 & 0 \\
\hline Health guides & 2 & 1 \\
\hline Surgical texts & 30 & 7 \\
\hline Public welfare & 5 & 1 \\
\hline \multirow{2}{*}{ Periodicals } & $G M$ & 9 & 9 \\
\cline { 2 - 4 } & $E M J$ & 28 & 9 \\
\hline
\end{tabular}

\footnotetext{
3 The best known is Samuel Pepys's (1633-1703) diary with considerable attention to his own illnesses. See also Chapter 6 in this volume.
} 


\begin{tabular}{|l|c|c|c|}
\hline & $P T$ & 14 & 8 \\
\hline Total & 262 & 66 \\
\hline
\end{tabular}

In compiling the LMEMT corpus, our selection criteria for texts to be included were text-external and we did not pay attention to text-internal aspects like embedded subgenres. Thus, the distribution of case studies or other subgenres is not regulated in any way and it is reasonable to assume that this accumulation of text samples reflects the status of the genre and reveals the sociohistorical contexts of individual case reports. Their distribution over different decades within the eighteenth century turned out to be uneven, too, as the majority of case narratives originate from the latter part. The number of case studies within each decade is shown in Figure 1:

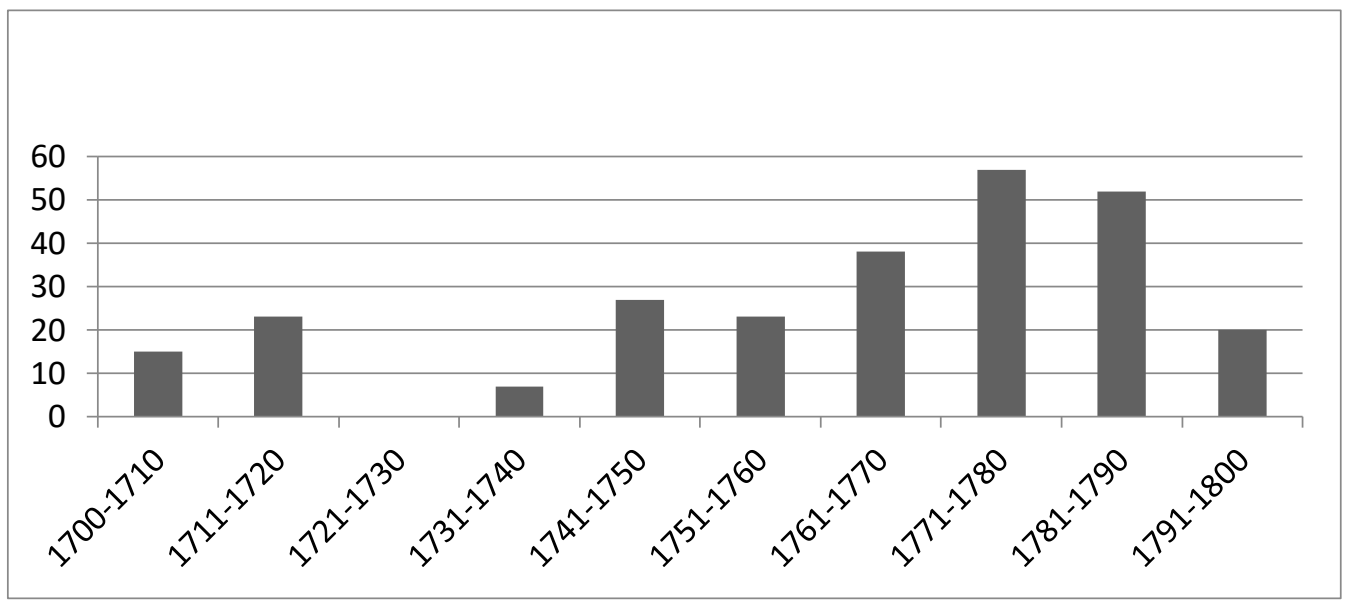

Figure 1. Number of analysed case studies per decade in LMEMT

Most case studies are found in texts published between 1761 and 1790, and each decade after 1741 includes at least 20 case studies. Prior to 1740, the frequencies are generally lower apart from between 1711 and 1720, and there are no case studies found in the 1720s. The number of different corpus texts with embedded case studies display a similar distribution, as the numbers are higher in the latter part of the corpus time line. Partly, this reflects the fact that there are more texts in the corpus from the later periods, but it may also signify a change in the underlying thought style - an assumption that is further assessed in our analysis (see Section 7.3).

\section{Theories and methods}

We shall pay attention to two different aspects of language use in eighteenth-century case studies, and our analyses in Section 7 follow the same plan. It is pertinent to begin this assessment with a structural comparison to natural narratives, as both often deal with questions of life and death; their structures are likely to have some common components. The second section mainly deals with personal pronouns that provide a key to the point of view. Methodologically, the structural analysis can be described as top down with its ready-made model of natural narratives and our analyses are qualitative. Further, the data is analysed with quantitative corpus methods, and the corpus queries make use of the AntConc program (Anthony 2014). Corpus linguistic methods are also used in the third section in charting the point of view, but qualitative analyses are also important as only a combination of both methods can yield valuable results. 


\subsection{Natural narratives}

The basis for our structural analysis comes from the insight that genres unfold in special ways with generic patterns that acquire conventionalized forms (see e.g. Eggins and Martin 1997). One of our research questions is whether the structure of these reports follows the model of natural narratives (Labov and Waletzky 1997 [1967]). The pattern was established in an empirical study with tape recordings on people's authentic accounts of events when their lives had been in danger: "[ $t]$ he basic narrative units ... are defined by the fact that they recapitulate experience in the same order as the original events" (Labov and Waletzky 1997 [1967]: 20-21). The model of natural narratives includes six moves in a specific order:

Abstract: what, in a nutshell, is the story about?

Orientation: who, when, where?

Complicating action: What happened and then what happened?

Evaluation: So what? How or why is this interesting?

Result or resolution: What finally happened?

Coda: That's it. (after Toolan 2001 [1988]: 148)

The first two steps, abstract and orientation, introduce the topic and the characters of the story. In medical texts, these parts give information on the patients and doctors, and they also describe the onset of the illness. The complicating action forms the main line of the narrative, relating the treatment of the patient in its various phases with an evaluation of the effectiveness of the cure; as a result, the patient usually either recovers or dies. Finally, the coda sums up the story and signals that the narrative has come to an end. An earlier analysis on EMEMT case studies showed them to follow the pattern of natural narratives fairly closely. Our assumption is that the trend continues in the late modern period, but there may be modifications.

\subsection{Point of view}

Narratives can be told from the perspective of the author or characters in the story. Fowler (1986:135) deals with fiction and distinguishes types of internal and external narrators with distinctive points of view: the most subjective viewpoint is achieved by internal first-person narration since the events and emotions are narrated through the main character's standpoint. In external types of narration, the author or narrator is more objective and does not report thought processes or inner monologues. Simpson (1993:55) further develops this model and recognizes two main points of view: the story can be written in the first person and the actions are narrated from the point of view of the main character, or the events can be reported in the third person without the narrator participating in the story. Our analysis of the point of view relies on corpus-linguistic methods in addition to qualitative reading. Corpus searches were made for the personal pronouns $I$ and we to examine their distribution across different corpus categories. In addition, cluster analysis was used to assess typical structures in which the first-person singular $I$ and plural we occur. The size of the cluster was set to include constructions from two to five words, and the minimum raw frequency was five; this method retrieved 169 cluster types with 2,326 cluster tokens. In addition, we paid special attention to the semantic classes of verbs to examine what type of actions are portrayed. 


\section{Analysis}

Case studies occur both in learned treatises and in works aimed at wider audiences in LMEMT. The results of our analyses are discussed below, moving from narrative analysis to point of view, and taking the sociohistorical backgrounds of authors and audiences into account.

\subsection{Narrative patterns}

Many of the case reports follow the form of natural narratives, and we chose Catherwood's $A$ new method of curing the apoplexy (1715) from the category of methods to represent the structure of the case studies. The author relates "Observations" to promote his cures by proving that previous methods of treating apoplexy had been insufficient. As extract (1) below shows, all six elements of natural narratives are present. The shifts in the structure have been marked using square brackets:

... What I have said I shall only confirm with two or three Observations, and that as concisely as possible.

Obs. 1.

[ABSTRACT] There was one Mr. Roach of Bristol, who for a long time had labour'd under an Asthma, attended with a violent Cough till almost suffocated; [ORIENTATION] but after he had expectorated this viscid Phlegm, was reliev'd: but the Disease increasing, and despairing of Relief, he apply'd himself to me, inform'd me he had been so afflicted for many Years, that at Spring and Fall he had very severe Fits of the Gout; so that what with one and t'other, he was render'd incapable of prosecuting any Business. [COMPLICATING ACTION] I exhibited Medicines of a warm attenuating kind, to disentangle and carry off the vitious Matter, promote Expectoration, fortify the Stomach and Lungs, which effectually compleated the Cure. [EVALUATION] After which he could endure the Fatigue either of walking or riding, was able to dispatch his Affairs with his usual Alacrity and Pleasure. [SECOND COMPLICATING ACTION] But since my Removal from Bristol, his old Indisposition returning afresh, he had immediate Recourse to his former Chip-in-Pottage Doctor, ... which he had no sooner taken with a Draught of Carduus Tea, [RESULT] but presently he complain'd of a Dizziness, and that every thing appear'd to him to have a circular Motion: which he had no sooner said, but he dropt down dead. [CODA] Some may imagine that this Accident was not owing entirely to the Emetic, but a Plethora; and had bleeding preceded, in order to have emptied the Vessels, the Patient might have been saved: which Objection, tho I could answer with several Instances, I shall only mention one. (Catherwood, A new method of curing the apoplexy, 1715: 22-23)

The aim of the "Observations" in Catherwood's work is to give proof to the arguments about the supremacy of the author's healing method. In general, the purpose of the case studies is mentioned at the beginning before the abstract, e.g. "What I have said I shall only confirm with two or three Observations." The case begins with the name of the patient, his town of origin and his disease: "Mr. Roach of Bristol, who for a long time had labour'd under an Asthma." Other pertinent information may follow, the most important being the age and social rank of the person and the date when the disease was attested. The abstract refers to the particular illness by its name and summarizes the main symptoms. The patient's introduction continues with an orientation that describes the progression of the disease in more detail. In general, the complicating action consists of the treatment, and here the author steps forth in first-person narration to describe the success of the cure. The narration escalates into a second complicating action with a conflict caused by a 
quack doctor who is accused of prescribing ineffective remedies and treatments ("he had immediate Recourse to his former Chip-in-Pottage Doctor"). The conflict can be interpreted as a warning against unauthorized practitioners and ineffective cures. Various steps of treatment are particularly common if the first cure is not successful. The unfortunate mistreatment in the above extract results in the patient's death. The coda addresses possible counter arguments on the cause of death.

The above case study serves to represent several others in LMEMT. All parts of natural narratives need not be present, but typically the information on the patient and the symptoms are narrated along with the treatment, the response to the cure and the end result. The style and the extent of the report vary according to who the eyewitness of the story is; some case studies rely on the scholastic mode of knowing by hearsay or citations from earlier works and letters, while others are based on empirical knowledge and the author's own experience. Some contain extremely long and detailed first-hand observations, describing the examination of the patient with a series of cures and responses to the treatment. These case studies provide daily or weekly reports on the patient and exhaustive explanations of the remedies and methods.

An example of a long case study with detailed observation is Goldson's treatise An extraordinary case of lacerated vagina (1787) from the category of midwifery. It presents an untypical account: the author describes the progression of the patient's labour first and, after her death, the dissection of her reproductive organs. The physicians observed the patient for 23 days (abbreviated as d):

(2) -22d.-The persons who watched with her during the night informed us, that she had been very restless; complained of great pain in her belly, with intense thirst, and that she had been constantly vomiting. Her countenance was greatly altered; ... the tenesmus still continued, but without any evacuations; her anodynes were repeated ...

-23d.-We found her more composed ... She continued in the same state until about eleven o'clock before noon, when she died, perfectly sensible. We obtained permission to open the body the same evening. The abdomen was much tumified. Upon making a longitudinal incision through the integuments, a quantity of confined air rushed out. The peritoneum was inflamed ... (Goldson, An extraordinary case of lacerated vagina, 1787: 19-21)

Each treatment and change in the patient's wellbeing is recorded, including complicating actions and evaluations. Later in the treatise, the author cites numerous earlier cases that he argues were caused by a lacerated vagina, too, thus pointing out the relevance of his teaching. The instructive purpose is clear, as the author relates the cause of the illness in detail so that subsequent cases of the same kind can be identified.

A closer examination of the material brings forth a new trend connected with the "experimental" thought style of the Enlightenment, in accordance with the increasing demand for reliance on the matter-of-fact principle in a documentary style of writing. Case studies written in this vein regularly alternate with experiments made by the author and contain accurate descriptions of the methods and phases of the study. Such examples are common in learned professional treatises in surgical and anatomical texts and scientific periodicals. In Kirkland's surgical work An essay on the methods of suppressing hamorrhages from divided arteries (1763), the case study is intertwined between numerous experiments:

(3) After this I made more experiments of the same kind ... it was easy to discover this contraction taking place by a gradual decrease of the stream of blood; but in August 1757 the following case gave a further light to this matter. Jos. 
Ayre of Caudwell, about twenty years of age, in being bled had the misfortune to have the humeral artery opened along with the basilic vein, and the operator with much difficulty suppressed the hæmorrhage by bandage: however a tumor with great pulsation soon began to arise in the part wounded, ... and determined me to perform the operation for the aneurism. The impulse of the blood against the ligature at the time of the operation was very great; ... but upon removing the dressings the third day afterwards, the pulsation could neither be seen nor felt ... whence I was led to conclude, that the artery had collapsed and gradually closed itself up to the nearest lateral branches, as the resistance towards the ligature abated from the blood passing through those vessels. -And it appeared to me selfevident that nature always took this step to suppress the hæmorrhage from divided arteries, when I reflected that the same circumstance constantly happens, when the umbilical vessels are divided at the birth of the foetus. However, as I did not look for the lateral branches in the experiments mentioned, I cut off another horse's tail near his body, and suppressed the hæmorrhage by pressing a few minutes with my fingers; and by a careful dissection the next day after he was killed, I found that the conclusion I had drawn was (in this subject at least) perfectly right. Is it not owing to this cause that an hæmorrhage does not follow those mortifications, where the greatest part of the limb is destroyed and separates? (Kirkland, $A n$ essay on the methods of suppressing hamorrhages from divided arteries, 1763: 4-6; emphasis in all examples ours)

Kirkland focuses on his observations on the patient and describes the surgical procedures. The patient remains in the background with only his name, age, and home town briefly mentioned. The author's attention is keenly focused on the experiments on haemorrhage, and as he hears of a new patient with the same disease, he proceeds to make further observations on horses. ${ }^{4}$

Some of the case reports are short and function as brief examples of a series of successful cures: they advertise medicines or methods and focus more on the effect of the cure than the procedure.

(4) REBECCA BROWN, Daughter of Jerry Brown of Coln Engain, Essex, Husbandman, aged 12 Years, had Several running Scropholous Sores about her Neck and Shoulders, otherwise a florid well looking Girl; my very easy Methods cured her in about Four Month. (Morley, An essay on the nature and cure of the King's evil, 1763: 34)

Morley lists cases of scrofula that he has treated. In general, he describes the patient's symptoms and positive reaction to the treatment; the examination of the patient is less relevant, and sometimes comments on the patient's looks are given. These treatises regularly chain brief case studies on various patients to underline the efficacy of cures. Testimonies from satisfied customers may also be included, with the patients' own stories about how their symptoms were relieved (see Section 7.2.2. on point of view below).

\subsection{Point of view}

Personal pronouns provide a key to the point of view in a text, and corpus linguistic methods are particularly suitable for tracing their occurrences. Verbs may follow in the active or in the passive voice, which is also important. Semantic fields of verbs and adjectives serve as indicators of stance,

\footnotetext{
${ }^{4}$ Experiments on animals were common at the time. Cf. experiments of blood transfusion on dogs in PT reports (EMEMT).
} 
and some sentence types convey affective meanings. Thus, the study of point of view includes multiple features, and both quantitative and qualitative assessments are needed.

\subsubsection{Point of view of the author}

Several factors contribute to whether a text exhibits a detached mode or shows personal involvement. The eyewitness of the story plays an important role: if the author reports a case where he acts as the agent, he is as a rule more involved than if the case is treated by somebody else. Special cases are provided by reports of illnesses in letters, as the communication channel promotes involvement so that the writer adjusts his narration to the conventions of letter writing with interpersonal features.

In addition, the point of view alters according to the audience and the purpose of writing. Case studies written for lay audiences exhibit close personal involvement. Affective language use is especially noticeable in texts aimed at promoting medicines and targeted at lay audiences. The purpose of such case studies is to advertise the efficacy of the remedies and to attract new buyers. The next Example (5) is taken from the most "popular" end of the scale as it is written by James Graham, a quack doctor, and intended for a heterogeneous lay audience. It focuses on the case of a certain Miss Beatt, who is said to be cured by Graham's medicines.

(5) About the beginning of last March, Miss Beatt was seized with a severe disorder which broke out on one side of her face ... in two or three weeks ... it had swelled to a monstrous degree ... The catastrophe of the scene being now at hand, and the young Lady herself, her affectionate father,

and her anxious friends, being alarmed and apprehensive of the most fatal consequences-the services of the Medical Gentlemen who attended her were dispensed with, and I was called in. The chilly shivering coldness ... encreased, now, very fast. - The terrible humour began to fall inward ... What was to be done? ... I immediately mixed a large vial of my NERVOUS AETHERIAL BALSAM, and another of my ELECTRICAL AETHER ... Of this mixture, I gave Miss Beatt spoonful after spoonful ... What were the effects of these bold-these great operations? -They were most happy!-They appeared miraculous! ... How very fortunate it was for Miss Beatt that I was personally present to direct the proper exhibition of the three great medicines-to which under God! she owes her life! ... (Graham, The guardian goddess of health, 1780: 27-29)

The structure follows that of a natural narrative. At the beginning, the patient is referred to by her name instead of using more neutral terms. The wordings refer to time and her body parts, and narrative elements such as "I was called in" are also found. However, what is exceptional in the extract above is the abundant use of vivid expressions: "The catastrophe of the scene", "chilly shivering coldness", "affectionate father", "the terrible humour" and the dramatic turns of the patient's "miraculous healing". The author enhances his own role by first-person narration: "I immediately mixed" and "I gave", and "[h]ow very fortunate it was for Miss Beatt that I was personally present". The names of the author's medicines are written with uppercase letters to attract attention and promote their sales.

Some other case studies with the same function make use of direct (or indirect) quotes by the participants of the story to enhance their dramatic representation. This device can be found e.g. in the following example from the category of regimens. In Bill of health (1785), the anonymous 
author advocates fasting, rest and drinking water. The narrative proceeds in the first-person singular and contains a dramatic complicating action with the apothecary, who threatens the patient "if he did not do it he was a dead man"; the author wins and his cure is successful. He emphasizes fresh air and water with a moderate diet and proves their efficacy beyond medicines (see Chapter 6 in this volume). The beginning adds a homely touch by mentioning a personal acquaintance:

(6) A neighbour of mine became very feverish, and his wife persuaded him to go to bed. I heard of it soon after, and gave him a visit, where I found the windows close shut, ... I drew open the curtains, ... and then opened the windows, ... upon which he soon told me his shortness of breath had left him. I persuaded him to drink some water, which he found did much refresh him; ... the apothecary came in, whom his wife had sent for, who, finding him about to drink the water, told him if he did do it he was a dead man; but, instead of forbearing, he drank it up in his presence: upon which the apothecary took his leave, and told him he would say no more to him. However, before night, the person got up, went abroad, and was cured of his fever. (Anonymous, Bill of health, 1785: 6-7; emphasis ours)

Distant involvement, on the contrary, is more typical of case studies written for professional audiences. In his Essays on the hepatitis and spasmodic affections in India (1787), Girdlestone writes about a case of an officer with dysenteric symptoms. The frame of the story is told in the passive voice, but when the doctor (who is the author) enters the scene the voice changes to the active ("I then saw him ... and found ..."), but returns to the passive in the description of the disease:

(7) An officer in his majesty's service ... was attacked with dysenteric symptoms. Having used salts, fomentations, glysters, opium, \&c. for eight days, without any effect, his case was thought to be mortal.

I then saw him; and, on examination, found the right lobe of his liver evidently diseased. He was immediately put upon a course of mercurial frictions ... The frictions were successfully continued; but the exhibition of a few grains of calomel ... affected the mouth so suddenly, and so violently, as to render the continuance of them impracticable. The dysenteric symptoms disappeared, but his mouth remained for several days very troublesome. He was sent to the Danish settlement on the coast for the reestablishment of his health ... On the idea that this pain was a spasm of the colon, fomentations, glysters, opium, and evacuations, were again put in practice. But the patient, finding all to no purpose, determined on having recourse to friction, though contrary to the advice of all his medical attendants.

This expedient again afforded him speedy relief; and he was restored to health by using it as freely as his mouth would permit. (Girdlestone, Essays on the hepatitis and spasmodic affections in India, 1787: 35-37; emphasis ours)

The patient is treated by various physicians, and the passive voice is prominent even when the author describes his own actions as a physician, e.g. "He was immediately put upon a course of mercurial frictions." The narration aims to be objective, although it makes it unclear who is attending the patient during the different steps of the treatment. Additionally, nominalizations such as "the exhibition of" and "the continuance of them" and noun phrases such as "The dysenteric symptoms" and "this expedient" as part of passive constructions place the focus clearly on the course of the illness and treatment, and thus, foreshadows the modern style of writing case studies.

The passive voice and nominalizations are repeatedly present in case reports aimed at professional readers, but nevertheless first-person narration is used in many learned texts, particularly where the authors explain their experiments in a chronological order. In these cases, the procedure is based on personal experience and carefully written down to serve as a model. This type of narration is found 
in surgical and anatomical texts and scientific periodicals and it conforms to the new scientific demand for replicability. The author of a case study in the EMJ is explicit about the different phases of his operation on a patient's tumour. He follows a chronological order and describes the course of action in detail in the first person:

(8) A Gentleman had been plagued with a tedious Tooth-ach, which occasioned a very hard Tumor ... By cutting the Gum between the Rootsof the rotten Tooth I made way for a thin Piece of Iron, which I pushed forcibly in between these Roots, and then thrusting it to a Side, I prised the one Root inwards out of its Socket ... A small Gimblet being immediately put into the farthest back Socket, I endeavoured to make it pierce into the antrum maxillare ... (EMJ 1747: 332; emphasis ours)

In addition to the first-person singular, the plural form we is found in cases where more than one physician is referred to (see Example (2)). In some of the instances, however, we is used as a device of involvement referring collectively to the reader and the author, especially at the beginning of the case study where the purpose of the report is stated and in the following generalizations (see Examples (11) and (12); Wales 1996). The following Figure 2 illustrates the frequencies of the personal pronouns $I$ and we in the case studies in the first and latter half of the eighteenth century:

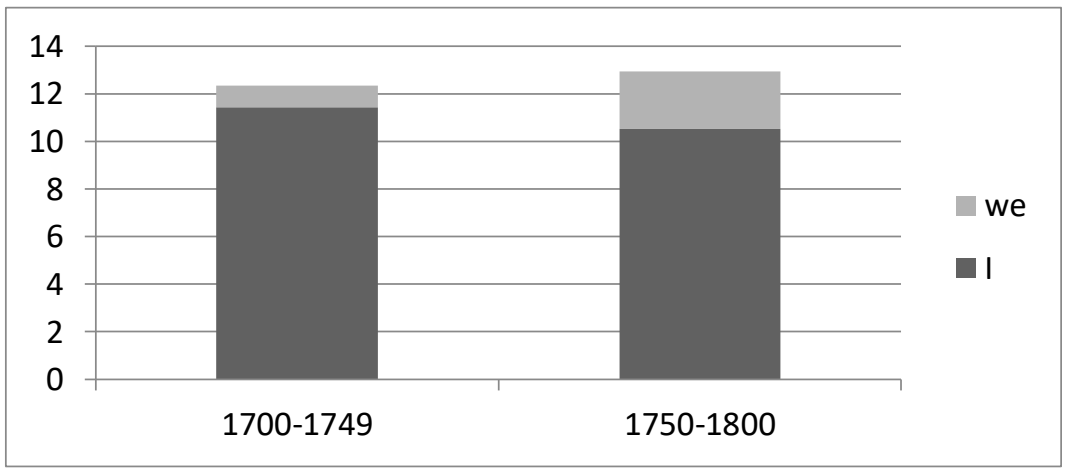

Figure 2. Diachronic distribution of the personal pronouns I and we in case studies (f./1,000 words)

The overall frequencies for the personal pronouns remain almost the same throughout the century (12.4 and 12.9 respectively), while the first-person plural we is somewhat more common in the later case studies. More noticeable differences are attested when the frequencies are examined according to corpus categories in Figure 3:

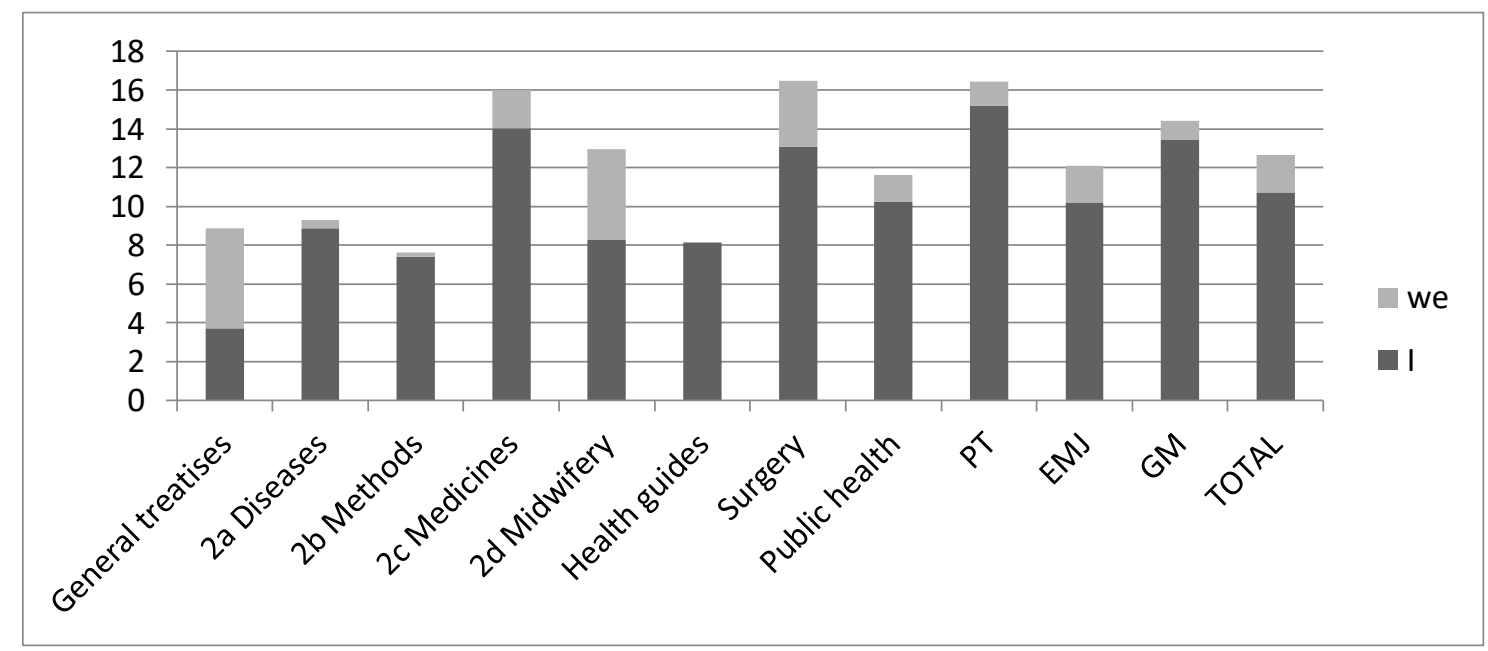


Figure 3. Distribution of the personal pronouns I and we across the corpus categories (f./1,000)

The normalized frequencies vary in each corpus category from 8 to 16 instances in 1,000 words, and the average frequency in all case studies is about 13. First-person narration is common in case studies in scientific periodicals, surgical and anatomical texts, therapeutic substances, and midwifery. Author-centred narration is found in all three periodicals, but with a difference: in the PT and EMJ the narrator is the physician, while in the GM it is often the patient who relates his case (see Section 7.2.2). Scientific periodicals employ author-centred discourse in experimental use, and a number of texts are written in the form of a letter, which increases personal involvement. In surgical and anatomical texts, the epistemological use is also noticeable, with the steps of the procedure explained in detail. In the midwifery category, the case study by Goldson (Case of lacerated vagina, 1787) relies on epistemological narration, although many other case reports in this category are aimed at a wide readership. In the category of therapeutic substances, narration in the first person is regularly based on advertising and appeals to lay audiences.

As a next step in our analysis, we examined the verbs in collocation with the pronouns $I$ and we. The most common clusters (ranging from two to five words) are I have and I was, which are rather neutral. Many clusters, however, portray the author in an active role providing treatment for the patient such as I gave (her an opiate), I took (twelve ounces of blood), I applied, I ordered (an emetic) and I advised as well as I made an incision. Further, clusters that refer to the physician visiting the patient are frequent, e.g. I was called to, I found (her in deep sleep). Other recurring verbs are private verbs expressing mental processes, such as I think, I thought, I am of opinion that, I judge, and I know, and clusters that are related to observation such as we observed and I saw (see Quirk et al. 1985: 1181). Private factual verbs are hence common, while personal pronouns occur less frequently with public verbs or other verb types such as emotive or suasive verbs. The authors are involved in the case reports, as they explain their observations and mental processes, and in evaluations of the effectiveness of their treatments.

\subsubsection{Point of view of the patient}

Most case reports are written by medical authors, but stories from the other side emerge in the eighteenth century. The GM had a wide lay readership of polite society (see Chapter 7 in this volume) and the patient's voice is heard for the first time. Readers sent medical contributions relating their own health problems and asked for help in their letters to the editor. In several cases, responses came from the floor and correspondence ensued with other readers through the editor, Mr. Urban, and his novel channel. The following Example (9) comes from the very end of the century, a reader relates his own case and proceeds to give advice to others suffering from the same problem. The writer recommends a moderate diet, reflecting the growing interest in regimen in the eighteenth century:

(9) Mr. Urban, April 10. YOUR Review on Dr. Bree's Enquiry on disordered Respiration induces me to send you my case, as it may throw some additional light on the subject, and assist those labouring under the like complaint with what I find relief from. Nearly 20 years ago, I was attacked with a pain about the præcordia, and a shortness of breath ... I take (in water) from 7 to 20,30, 40 drops [of laudanum], or more, according to the violence or duration of the paroxysm ... And here give me leave to hint to the faculty to avoid the use of perfumes, as I have frequently suffered by those gentlemen ... 
Accustoming my-self to a great deal of air preserves me from catching cold; and I am necessarily obliged to a moderate diet. Water has been my constant beverage for many years, though I do not find a glass of wine occasionally hurts me ...

This account, Mr. Urban, I leave to your judgement to publish to your medical readers, if you think it will be of any utility to the investigation of the subject. (GM 1798: 294-296)

The motivation of the author in sharing his case is philanthropic in accordance with a concern for the common good. The case is narrated in the first-person singular and letter writing conventions are obeyed e.g. in the address and the polite request at the end, which leaves room for the editor to comply or not to comply.

Besides the GM, the patient's voice is heard in some other categories (methods and therapeutic substances). Robert Brand, a truss maker, introduces his elastic trusses in The true method of reducing ruptures (1771; in surgical and anatomical texts), and includes testimonies not only from surgeons but from patients, too. The following was written by a patient in the form of a "declaration", with further verification by a justice of the peace, testifying that the cure is indisputable:

(10) "IN justice and gratitude to Robert Brand, Truss-maker, in Aberdeen, I acknowledge that I have had a Rupture for these five years; ... I had a Truss purchased at London for me by Mr. Rose, the King's Receiver in the island; which I wore, but with great pain, ... until about a month ago, I purchased one from Mr. Brand, being a single Truss and fitted for the right side, which has answered the intent, by giving me no pain in my walking, keeps up the Rupture, and without the incumbrance of a Thigh-strap: Is attested to be truth by me, this 30th day of May, 1764.

alexander forbes."

Aberdeen.

"THE above declaration is attested by me, John Dye, of Tilligrieg, one of his Majesty's Justices of the Peace for the County of Aberdeen,

JOHN DYE, J. P."

Aberdeen, May 30, 1764. (Brand, Reducing ruptures, 1771: 11-12)

An example of patients' contributions is also found in the category of diseases. In King's evil, Morley narrates his cure of Ann Mead. The case report is followed by a letter from the patient, quoted verbatim: "by God's Blessing and your Kindness to me, I am quite restored to Sight and I return you my Sincere Thanks for the Trouble you gave yourself on my Behalf, having received that Benefit from you which I could not find from Several Doctors" (1763: 37). The account praises the author and functions as a testimony to the efficacy of the cure.

The roles of the physician and the patient become intertwined in cases where the doctor is both the narrator and the patient. E.g. in Effects of water (1797), James Currie (a physician) reports the case of Dr. Wright, a physician, infected with fever on board a ship, who cured himself by using waters. He reports on his daily observations in his dual role of healer and patient.

\subsection{Overall developments: Towards generalizations}

Some diachronic developments can be detected in our material. The roles of case studies change towards the end of the century, from accounts of individual cases to reports with broader 
generalizations based on multiple examples. ${ }^{5}$ One of the prevailing strategies is to list short references to numerous case studies that support the author's argument. The anonymous Power of nature and art (1753) provides a very early example of the modern probabilistic thought style in medicine. It discusses the dangers of Robert James's fever powder. ${ }^{6}$ The author draws attention to 27 cases published in the earlier work by James and provides summaries of them in an attempt to give a statistical basis for the conclusions. The narrative structure of these summaries consists of the patient's name and the dose of the powder and its effects. The numerical information is summarized at the end:

(11) 33. Miss. E. had no sensible operation with three doses ... 38. Mr. D. had a copious sweat, for four-teen hours; and three stools. Thus we may observe, that in eight cases, the powder both vomited, purged, and sweat ... In seven cases, it operated by sweats, and purging ... In three, it vomited and sweated; and in three more, it sweat only. Three also it vomited and purged, in one moderately, in the others, it vomited three or four times, and purged several; in one case it purged only, and in two had no operation at all. So that out of twenty seven cases, it operated by stool in nineteen, and in ten of them smartly, and considerably. These are the general effects and operations which followed the taking this medicine ... and may we not from hence fairly conclude, that in those cases, where vomiting, purging, and sweating are pernicious, (and many such there are) that the use of this powder should be suspended? (Power of nature and art, 1753: 49-50; emphasis ours)

On the basis of the calculations, the author questions whether the powder should be banned in the future. The trend is present in other case studies, too, as they note similar cases supporting their view and comment on general tendencies. Thus, the focus shifts from individual cases to more general concerns, where the total number of patients is more important. This development increases the total number of case studies in the latter half of the eighteenth century, along with the growing importance of experimental case reports. Multiple case studies also become commonly used as a basis for generalizations on the course of illnesses, e.g. An inquiry into the nature, cause and cure of the croup (1765) by Francis Home presents numerous cases and underlines their power when put together as evidence for an account of the general course of the illness. Methods and conclusions are based on facts: "the method such as is used in mathematics and natural philosophy, for discovering unknown truths" (see below). The presentation begins with case studies and finishes with conclusions of a wider scope:

(12) THESE are all the cases, that I have kept an account of, or received from others. Tho' few, they are leading ones, and sufficient to establish many material facts and circumstances ... We will now draw, from them, some conclusions ... If we add any reasoning, to set these conclusions in a clearer light, we shall keep as close as possible to settled experiment; and shall give it only as probable conjecture, finding fault with no person who may reason differently.

\footnotetext{
5 The tendency was earlier attributed to the nineteenth century (Taavitsainen and Pahta 2000: 61).

${ }^{6}$ Robert James was an English physician, who patented his fever powder in the mid-eighteenth century. The fever powder was meant to cure various illnesses and it was the most popular patent medicine of the time, although its efficacy was also regularly questioned (see D. Porter and R. Porter 1989: 129).
} 
COROLLARY I. It seems easy, in general, to distinguish the Croup from all other diseases hitherto described. A peculiar sharp shrill voice, not easily described ...

$\cdots$

WE have now brought our Inquiry to a conclusion. The facts, we hope, will appear curious, exact, and sufficiently numerous for our purpose; the method such as is used in mathematics and natural philosophy, for discovering unknown truths; and the conclusions new, surprising, and naturally arising from the facts. (Home, Croup, 1765: 32, 59-60; emphasis ours)

A further step in the development is found in Rollo's Diabetes mellitus (1797). The author narrates two case studies on diabetes in the first two sections, extending over several pages. The progression of the disease, the methods, and generalizations are presented in separate chapters after the case reports entitled General and comparative inferences resulting from both cases. This chapter contains numbered facts such as "1st THAT the Diabetes Mellitus is a disease of the Stomach, \&c. proceeding from some morbid change in the natural powers of digestion and assimilation". Atkinson (1992:348-349) finds a similar differentiation of the structural parts in late eighteenth and early nineteenth-century case studies in the Edinburgh Medical and Surgical Journal, and it can also be encountered in specific treatises in LMEMT.

\section{Conclusions}

The study aimed at analysing the diachronic development of eighteenth-century case studies by considering their function, narrative structure, specific linguistic elements, and point of view as well as relating the developments to wider changes in the underlying thought styles. Our assessment shows that case studies continue to be an important part of medical writing in the eighteenth century. The main function of the genre, to disseminate knowledge on diseases and successful treatments as well as present unusual cases, continues in LMEMT. Some new functions can, however, be detected. Case studies are used as veiled advertisements to introduce new remedies and persuade readers to buy the products. Further, experimental case reports become common, and references to multiple case studies are made to gather numerical information in order to make generalizations. This tendency is also reflected by the growing number of case studies during the latter half of the corpus timeline. Case studies thus gain new functions and remain in the centre of medical writing.

The pattern of natural narratives continues in the eighteenth century and case studies are almost regularly introduced by a statement of purpose with ensuing basic information of the patient and the symptoms of the disease. The series of cures, evaluation of the treatment, and outcome form the core part of many case reports. Formulaic writing conventions can further be detected on the level of the lexis, as many repeated word strings are used in texts of this genre throughout the century. The case studies contain many narrative elements, as they narrate events in time and make many references to the text-external reality, alluding to the patients, body parts, and medicines. Thus, several genre conventions with established structure and wordings continue in the Late Medieval and Early Modern English periods.

Yet, there is a great deal of variation in their linguistic realizations, especially in the expressions of the point of view and in the overall styles of writing, whether detached or involved. In general, the narration differs according to who the eyewitness of the story is. The extent of detail and the focus 
may also vary so that texts range from comprehensive treatises to short accounts. The different target audiences emerge as an important sociolinguistic factor causing variation: professional texts employ a more detached style of writing with the passive voice and nominal constructions; through them the author detaches himself from the narration and focuses on symptoms and medical procedures. In contrast, case studies targeted at lay audiences employ a more involved style with first-person narration. The outermost end of the scale with affective language use is found especially in case reports that advertise remedies. The increased involvement gains affective overtones by using first-person narration combined with emotional devices such as exclamatory sentences, direct quotes, and vivid adjectives.

Diachronic analysis of the personal pronouns $I$ and we showed that their overall frequencies remained fairly constant throughout the eighteenth century, although the plural form became more frequent during the later decades. According to Atkinson (1992:346), author-centred discourse with the first-person $I$ and active verbs declined in the EMJ in the latter half of the nineteenth century, when case studies started to rely more on numerical information and on summaries of cases instead of detailed information on individual patients. Taavitsainen and Pahta (2000) notice a similar development with nominalizations that contribute to the detached writing style. The present study, however, shows that author-centred discourse continues to be important in the case studies of LMEMT, but there are distributional differences across the corpus categories, so that involved and detached styles of writing vary according to the text categories and according to the functions of writing in addition to target audiences. In general, detached linguistic elements prevail in case reports aimed at learned readers already in the eighteenth century.

First-person narration, however, is used in a special function in some learned case studies that evolve into experiments. The first person is used to narrate the author's empirical experiments with findings. This usage can be related to Royal Society experimental reports in the PT to more profound changes in medical thought styles into emphasizing enquiry. Medicine had begun to rely more on empirical experiments and replicable methods, and further enquiries were needed. This style of narration in case studies is found especially in the categories of surgical and anatomical texts and scientific periodicals, and a noticeable feature is that the narration alternates between experiments and case studies in the author's explanations of his thoughts and methods. In general, the analysis of the clusters with personal pronouns suggests that authors narrate their private thought processes in addition to portraying themselves in an active role in treating patients. Our conclusion is that the special function of experimental case reports promotes the use of authorcentred discourse even in professional texts.

Most authors in LMEMT are medical professionals, but a development towards lay participation is attested in this century. This change is particularly noticeable in the GM in which patients narrate their own cases in letters to the editor, though the actual target group is other readers (see Chapter 7 in this volume). Patients' own narrations are also encountered in specific treatises, as authors publish letters sent to them from patients; they recount their symptoms and the course of the illness, testifying to the efficacy of specific medicines or methods of treatment developed by the author. These instances demonstrate how the patients achieve a more active role in medicine, as instead of being only objects of treatment they begin to publicly evaluate cures and methods from their own point of view.

Diachronic changes on how the genre of case studies was considered in medical thinking can be attested as well. In the latter half of the eighteenth century, the focus begins to shift from accounts of individual cases into multiple case reports and further to generalizations on the courses of illnesses. These changes take place especially in texts of specific treatises, leading the way to new 
practices. An increase in the number of case studies in the later decades is partly due to the simple fact that there are more texts in the corpus from that period, but this change in the underlying thought style may also have contributed as multiple case studies were used as evidence to enhance the credibility of the statements. Authors begin to emphasize quantitative methods used in mathematics and natural philosophy and discuss these views openly after presenting multiple case studies.

Scientific journals changed the communication practices between medical professionals. The EMJ (from the 1730s) and the PT (1665-) were scientific periodicals aimed at professional audiences. The PT was a general scientific journal, but the authors of case studies were mostly physicians. The EMJ was strictly focused on professional top medicine, representing the new groundbreaking channel of knowledge distribution among the profession. Interestingly, some of the developments such as experimental case studies and quantification are also attested in other more traditional corpus categories, in specific treatises and in surgical and anatomical texts. Monographs were still the most important channel for disseminating knowledge of novel developments of professional issues in medicine.

Previous work on case reports has dealt with MEMT and EMEMT and the nineteenth and twentieth centuries. This chapter aimed to fill this gap in previous research, and the LMEMT corpus provides numerous case studies for analysis. The findings indicate that the writing conventions of case studies continue from earlier periods, following the structure of natural narratives. However, numerous developments can be recorded, as the reports evolve towards experiments and statistical methods with general conclusions about illnesses and treatments; the point of view of the patient additionally becomes visible in the texts. The case studies further differ in the various corpus categories, indicating, for instance, that the audience has an important effect on the point of view of the author. Hence, a continuous line of linguistic realizations of case studies is slowly emerging, but further details are still needed for a full understanding of the developments. ${ }^{7}$

\section{References}

Anthony, Laurence. 2014. AntConc 3.4.3. Corpus software. Tokyo, Japan: Waseda University. See $<$ http://www.laurenceanthony.net/>

Atkinson, Dwight. 1992. The evolution of medical research writing from 1735 to 1985: The case of the Edinburgh Medical Journal. Applied Linguistics, 13. 337-74.

Biber, Douglas. 1995. Dimensions of Register Variation. Cambridge: Cambridge University Press. Biber, Douglas, Stig Johanson, Geoffrey Leech, Susan Conrad and Edward Finegan. 1999. Longman Grammar of Spoken and Written English. London: Longman.

Class, Monika. 2014. Introduction. Medical case histories as genre: New approaches. Literature and Medicine, 32.1. vii-xvi.

Conboy, Martin. 2017. British popular newspaper traditions: From the nineteenth century to the first tabloid. In Minna Palander-Collin, Maura Ratia \& Irma Taavitsainen (eds.), Diachronic Developments in English News Discourse. Amsterdam: John Benjamins.

\footnotetext{
7 This applies particularly to the first half of the nineteenth century, as texts of only one year (1820) in the EMJ were covered by Atkinson (1992).
} 
Crombie, Alistair Cameron. 1994. Styles of Scientific Thinking in the European Tradition: The History of Argument and Explanation, Especially in the Mathematical and Biomedical Sciences and Arts, vols. 1-3. London: Duckworth.

Dear, Peter. 1991. Narratives, anecdotes and experiments: Turning experience into science in the seventeenth century. Peter Dear (ed.), The Literary Structure of Scientific Argument: Historical Studies. Philadelphia, PA: University of Pennsylvania Press. 135-163.

Eggins, Suzanne and Martin, J. R. 1997. Genres and registers of discourse. In Teun A. van Dijk (ed.), Discourse as Structure and Process. London: Sage Publications. 230-56.

Fowler, Roger. 1986. Linguistic Criticism. Oxford: Oxford University Press.

Gries, Stephan Th. 2008. Phraseology and linguistic theory: A brief survey. In Sylvaine Granger \& Fanny Meunier (eds.), Phraseology. An Interdisciplinary Perspective. Amsterdam: Benjamins. 3-25.

Labov, William and Joshua Waletzky. 1967/1997. Narrative analysis: Oral versions of personal experience. In J. Helm (ed.), Essays on the Verbal and Visual Arts: Proceedings of the 1966 Annual Spring Meeting of the American Ethnological Society. Seattle: American Ethnological Society. 12-44. Reprinted in Journal of Narrative and Life History, 7. $3-$ 38.

Porter, Dorothy and Roy Porter. 1989. Patient's Progress: Doctors and Doctoring in EighteenthCentury England. Stanford: Stanford University Press.

Simpson, Paul. 1993. Language, Ideology and Point of View. London: Routledge.

Sinclair, John. 1991. Corpus, Concordance, Collocation. Oxford: Oxford University Press.

Taavitsainen, Irma. 2011. Medical case reports and scientific thought-styles. Revista de Lenguas para Fines Específicos. (Special issue edited by Francisco Alonso Almeida.) 75-98.

Taavitsainen, Irma. 2012. Medical news in England 1665-1800 in journals for professional and lay audiences. In Birte Bös and Lucia Kornexl (eds.), Changing Genre Conventions in Historical English News Discourse. Amsterdam: John Benjamins. 135-159.

Taavitsainen, Irma and Päivi Pahta. 2000. Conventions of professional writing: The medical case report in a historical perspective. Journal of English Linguistics, 28.1. 60-76.

Wales, Katie. 1996. Personal Pronouns in Present-Day English. Cambridge: Cambridge University Press.

Wear, Andrew. 2000. Knowledge and Practice in English Medicine, 1550-1680. Cambridge: Cambridge University Press.

Werlich, Egon. 1983. A Text Grammar of English. Heidelberg: Quelle and Meyer. 